\title{
Advances in preclinical therapeutics development using small animal imaging and molecular analyses: the gastrointestinal stromal tumors model
}

\author{
M. A. Pantaleo $\cdot$ L. Landuzzi $\cdot$ G. Nicoletti $\cdot$ C. Nanni $\cdot$ S. Boschi · \\ G. Piazzi - D. Santini - M. Di Battista - P. Castellucci · F. Lodi · \\ S. Fanti · P.-L. Lollini · G. Biasco
}

Received: 31 July 2008/Accepted: 16 January 2009/Published online: 19 February 2009

(c) The Author(s) 2009. This article is published with open access at Springerlink.com

\begin{abstract}
The large use of target therapies in the treatment of gastrointestinal stromal tumors (GISTs) highlighted the urgency to integrate new molecular imaging technologies, to develop new criteria for tumor response evaluation and to reach a more comprehensive definition of the molecular target. These aspects, which come from clinical experiences, are not considered enough in preclinical research studies which aim to evaluate the efficacy of new drugs or new combination of drugs with molecular target. We developed a xenograft animal model GIST882 using nude mice. We evaluated both the
\end{abstract}

M. A. Pantaleo $(\varangle) \cdot$ M. Di Battista · P.-L. Lollini · G. Biasco Department of Hematology and Oncology Sciences

"L.A.Seragnoli", Sant'Orsola-Malpighi Hospital,

University of Bologna, Via Massarenti 9, 40138 Bologna, Italy

e-mail: maria.pantaleo@unibo.it

URL: http://www.giststudygroup.it

L. Landuzzi · G. Nicoletti

Laboratory of Oncologic Research,

Istituto Ortopedico Rizzoli, Bologna, Italy

C. Nanni · P. Castellucci $\cdot$ S. Fanti

Nuclear Medicine Service, Sant'Orsola-Malpighi Hospital,

University of Bologna, Bologna, Italy

S. Boschi · F. Lodi

PET Radiopharmacy-Nuclear Medicine Service,

Sant'Orsola-Malpighi Hospital, University of Bologna,

Bologna, Italy

G. Piazzi

Centre of Applied Biomedical Research (CRBA),

Sant'Orsola-Malpighi Hospital, University of Bologna,

Bologna, Italy

D. Santini

Pathology Unit, Sant'Orsola-Malpighi Hospital,

University of Bologna, Bologna, Italy molecular and functional characterization of the tumor mass. The mutational analysis of KIT receptor of the GIST882 cell lines and tumor mass showed a mutation on exon 13 that was still present after in vivo cell growth. The glucose metabolism and cell proliferation was evaluated with a small animal PET using both FDG and FLT. The experimental development of new therapies for GIST treatment requires sophisticated animal models in order to represent the tumor molecular heterogeneity already demonstrated in the clinical setting and in order to evaluate the efficacy of the treatment also considering the inhibition of tumor metabolism, and not only considering the change in size of tumors. This approach of cancer research on GISTs is crucial and essential for innovative perspectives that could cross over to other types of cancer.

Keywords Gastrointestinal stromal tumors (GISTs) . Tyrosine kinase (TK) inhibitors · Small animal PET · 18-Fluoro-deoxiglucose (FDG) . 18-Fluoro-deoxythymidine (FLT)

\section{Introduction}

In the era of molecular target therapies for cancer, some relevant and novel aspects from the clinical setting should be considered for the in vivo experimental studies aimed at the development of new therapeutic strategies. The need to define the molecular target and the new concepts on response assessment to treatment are the two most important ones. An example is demonstrated with gastrointestinal stromal tumors (GISTs). In fact, in the last few years for the first time clinical experiences on GISTs patients highlighted both these aspects. GISTs are characterized by oncogenic mutations of KIT or platelet-derived growth 
factor receptor (PDGFr)-alfa resulting in a constitutive activation of their downstream signalling which principally includes the control of cell proliferation [1, 2]. Agents such as imatinib and sunitinib, tyrosine kinase (TK) inhibitors specifically directed against KIT and PDGFr-alfa receptors, dramatically changed the natural course of the disease of patients affected by metastatic or inoperable GIST and lead to the possibility to treat cancer with target therapies [3, 4]. Moreover, the tumor response cannot be still evaluated only using the traditional response evaluation criteria in solid tumors (RECIST) [5, 6]. Notwithstanding that both these advances are well considered in the clinical setting of medical oncology, they are still lacking in most of the experimental studies. The preclinical development of new drugs or combination of drugs with molecular targets should be planned with a modern approach based firstly on the use of advanced animal models.

The aim of this study is the development of a xenograft GIST animal model including molecular analyses for both target and molecular imaging technologies such as small animal positron emission tomography (PET) for tumor metabolism evaluation.

\section{Materials and methods}

\section{Cells}

The human GIST cell line GIST882 was kindly provided by Dr. Jonathan A. Fletcher, Harvard Medical School, Boston, Massachusetts, USA. Cells were routinely cultured in RPMI 1640 supplemented with $15 \%$ fetal bovine serum and were maintained at $37^{\circ} \mathrm{C}$ in a humidified $5 \% \mathrm{CO}_{2}$ atmosphere. All medium constituents were purchased from Invitrogen, Milan, Italy.

\section{Cytofluorometric studies}

GIST882 phenotype was studied by means of indirect immunofluorescence and cytofluorometric analysis. The following primary mouse monoclonal antibodies were used: anti- human KIT clone YB5.B8 (Pharmingen, San Diego, CA); anti- human HER-1 (EGF-R) clone 528 (Oncogene Research Products, Uniondale, NY); antihuman HER-2 clone MGR-3; anti- human HER-3 clone SGP1 (NeoMarkers, Fremont, CA); anti- human IGF-IR clone $\alpha$ IR3 (Calbiochem). The secondary antibody was Alexa Fluor $488 \mathrm{~F}(\mathrm{ab})_{2}$ fragment of goat anti-mouse IgG (Invitrogen, Milan, Italy). After the final washings, cells were resuspended in phosphate-buffered saline containing $1 \mu \mathrm{g} / \mathrm{ml}$ of ethidium bromide to gate out dead cells and were subjected to cytofluorometric analysis with a FACScan (Becton Dickinson, St. Jose, CA).
KIT and PDGFRA mutational analysis in GIST882 cells

Genomic DNA was isolated from GIST882 cells using Blood \& Cell Culture DNA Midi Kit (Qiagen, Valencia, CA), according to manufacturer's instructions. KIT exons 9, 11, 13, and 17 and PDGFRA exons 12 and 18 were amplified by PCR and screened for mutations by denaturing high-performance liquid chromatography (DHPLC, Wave, Transgenomic, Omaha, NE). DNA sequencing of the mutated c-KIT or PDGFRA was done for exons with a mutated profile at DHPLC using $\mathrm{CEQ}^{\mathrm{TM}}$ 8000 Genetic Analysis System (Beckman Coulter, Fullerton, CA).

Mice

Athymic Crl:CD-1-Foxn1 $1^{n u / n u}$ mice (referred to as nude mice) were purchased from Charles River Italy and kept under sterile conditions. Experiments were authorized by the institutional review board of the University of Bologna and done according to Italian and European guidelines.

To study tumorigenicity GIST882 cells $\left(3 \times 10^{6}\right.$ and $30 \times 10^{6}$ ) were injected subcutaneously (s.c.) in the right hind leg or intra peritoneum (i.p.). Tumor incidence and growth were evaluated weekly. Neoplastic masses were measured with calipers; tumor volume was calculated as $\pi[\sqrt{ }(a b)]^{3} / 6$, where $a=$ maximal tumor diameter and $b=$ tumor diameter perpendicular to $a$. At sacrifice samples of the tumor mass were fixed in $10 \%$ phosphatebuffered formalin or fronzen in liquid nitrogen.

In vivo imaging studies

Imaging studies were performed using small animal PET tomograph (GE, eXplore Vista DR). Animals did PET scans after gas anaesthesia (Sevofluorane 3-5\% and oxygen $11 / \mathrm{min}$ ). The detection of a GIST tumor mass and the study tumor metabolism and proliferation were performed using two tracers: 18-fluoro-deoxiglucose (FDG) for glucose metabolism and 18-fluoro-deoxythymidine (FLT) for cell proliferation. FLT studies were performed 4 days after FDG acquisition.

Tumor biological studies

Histological evaluation and KIT immunohistochemical (IHC) analysis were performed in order to confirm the GIST diagnosis. The mutational analysis of KIT receptor was performed again in order to confirm that the mutational characteristic was still present after in vivo cell growth. 
Fig. 1 Cytofluorometric analysis of c-kit, HER-1, HER-2, HER-3 and IGF-IR expression in GIST882 cells. Open profile represents cells stained with secondary antibody alone; solid profile represents cells stained with the specific primary antibody. In each panel the ordinate represents the number of cells. Data from an experiment representative of at least two similar experiments

\section{Results}

By means of indirect immunofluorescence and cytofluorometric analysis we studied the growth factor receptor expression profile of GIST882 cells including expression analysis of KIT, some HER/erbB family receptors and IGF-IR. As indicated by the cytofluorometric profile GIST882 cells expressed KIT as well as HER-1 (EGF-R) and HER-2 proteins (Fig. 1). Surface expression of HER-3 proteins and IGF-I R were not detectable. The expression of other growth factor receptors and TKs suggests that additional target therapies could be combined to KIT target therapy in GIST tumors and could be preclinically evaluated in this tumor model.

The mutational analysis, as expected, showed a mutation on KIT receptor exon 13 (homozygous mutation-K642E) (Fig. 2).

The xenograft tumor model was established by s.c. or. i.p. injection of GIST882 cells into nude mice. No tumor growth was seen after i.p. injection. After subcutaneos injection, growth of tumor became evident after a median latency time of 41 days in the case of injection of $3 \times 10^{6}$ cells and 25 days in the case of injection of $30 \times 10^{6}$ cells. The percentage of tumor uptake was $80 \%$ (4 tumor bearing animals out of 5) at the dose of $3 \times 10^{6}$ cells and $67 \%(2$ tumor bearing animals out of 3 ) at the dose of $30 \times 10^{6}$. Tumor growth was very slow and sometimes indolent as shown by the in vivo growth curve (Fig. 3 ). In the group that received $3 \times 10^{6}$ cells 2 animals did not show any progressive growth.

PET analysis was performed at 88 days in the $3 \times 10^{6}$ treated group. The FDG and FLT was well uptaken in all tumor mass (Fig. 4). Histological evaluation and KIT (IHC) analysis confirmed the GIST diagnosis (Fig. 5). Mutational analysis of tumor samples showed again the mutation on KIT receptor exon 13 (Fig. 2).

\section{Discussion}

In the last years, the large use of target therapies in the treatment of cancer highlighted the urgency to use new imaging technologies, to develop new criteria for tumor response evaluation and to reach a more comprehensive definition of the molecular target. The experimental studies aimed to the development of new drugs for cancer treatment should consider all these aspects.
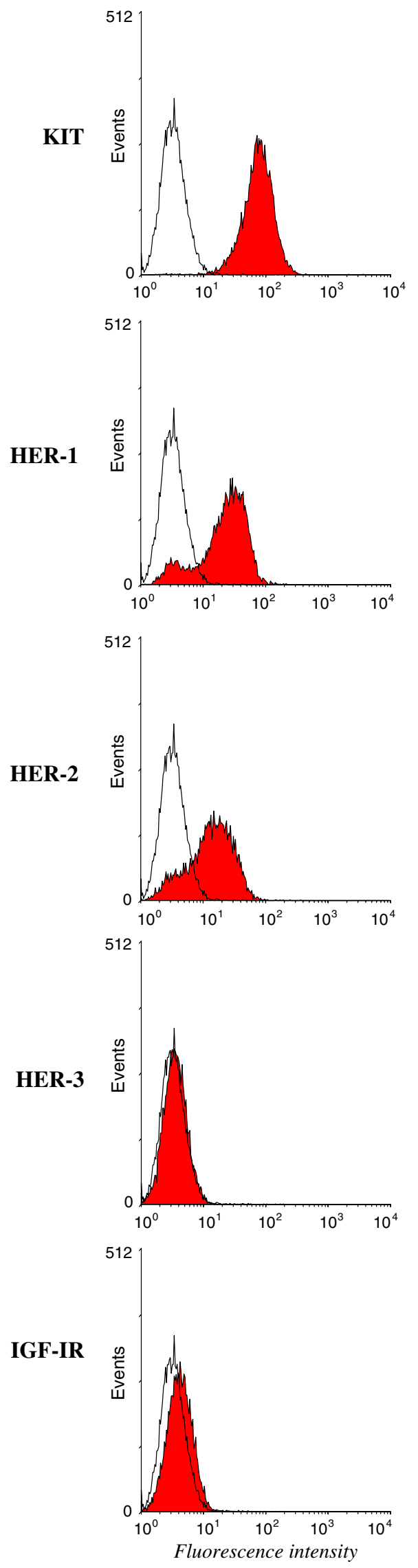
Fig. 2 Molecular KIT analysis with a mutation in position 70040 of exon 13 (substitution of a guanosine instead adenine). a Normal genomic amino acids KIT sequences. b Molecular analysis of tumour of a xenograft GIST882 mice after sacrifice. c Molecular analysis of cancer GIST882 cell line before injection
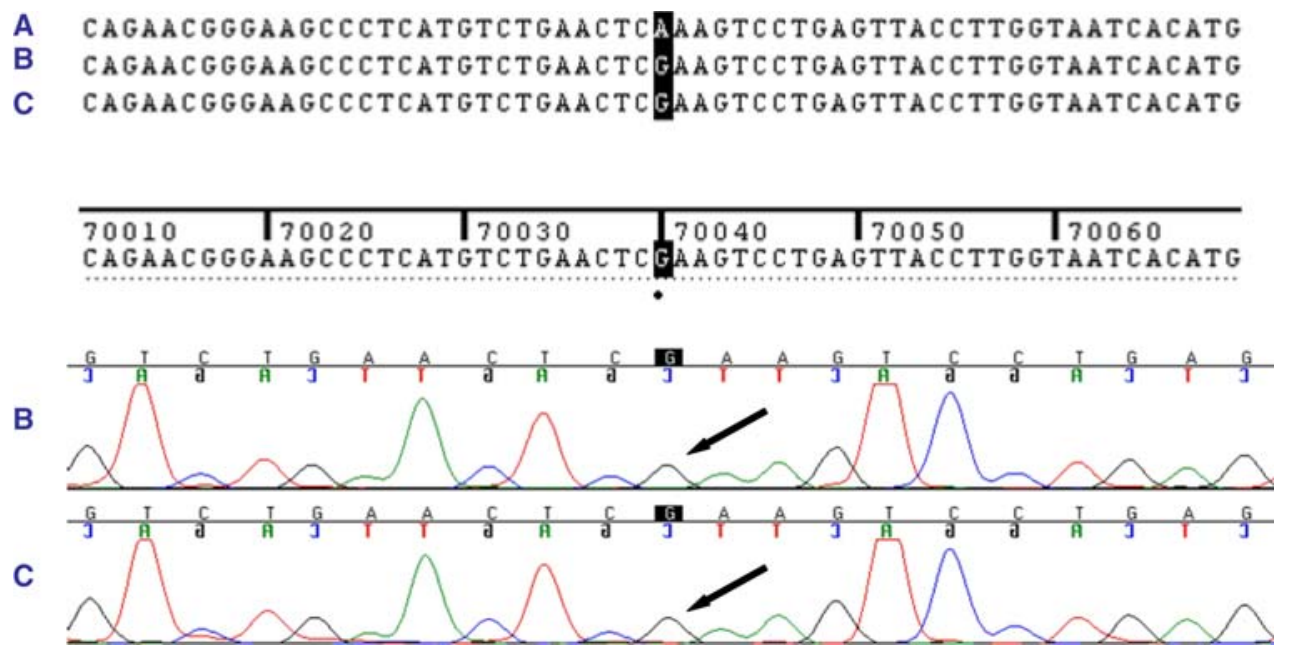

We developed a xenograft model of GIST characterized by the definition and the maintenance of the molecular target and by a good evaluation of tumor metabolism. This model seems suitable for the development of new drugs or combination of drugs for GIST treatment because it has both the functional and molecular characterization. Imaging studies with FDG provide information on glucose metabolism associated with a standard measurement of macroscopic size of the tumours. Moreover, considering that TK inhibitors strongly reduce cell proliferation, a radiotracer specifically targeting this biological effect as FLT could also be used. FLT has already demonstrated to be a tool for monitoring antiproliferative drugs in oncology [7]. Both FDG and FLT tracers should be used for assessing the biological markers for targeted therapies in GISTs in the preclinical setting.

The strength of this first consideration is markedly underlined by clinical experiences. As well known, the evaluation of tumor response to target therapies cannot be based only on the change in size of lesions [8]. The traditional RECIST criteria that are still considered the standard method for assessment of anticancer treatment activity do not provide information on biological, vascular or metabolic variations [9]. They should be associated with other methods in order to detect modifications of the biological profile of the tumour after therapy. Approximately $80 \%$ of patients affected by GISTs have a durable disease response with TK inhibitors, but most of the time imatinib does not lead to lesion shrinkage, on the contrary it may induce intra-lesion functional or biological modifications. The CHOI criteria using only contrasted-enhanced computed tomography (CT) have been recently studied evaluating both the tumour size and density variations after imatinib [5, 6]. About functional imaging, the uptake of FDG on PET may strongly decrease even $24 \mathrm{~h}$ after imatinib or sunitinib administration and the decrement

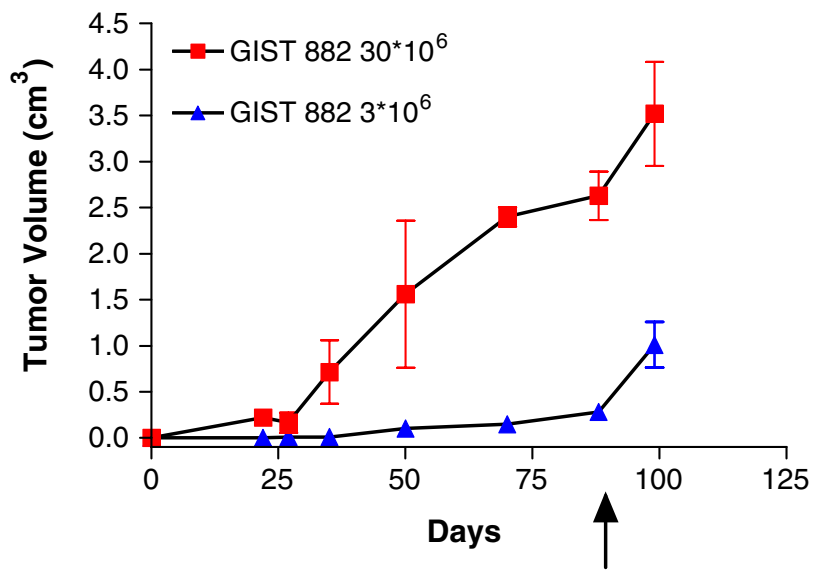

Fig. 3 In vivo growth curve of GIST882 tumors. Negative animals were not included in the curve. The arrow indicates the time when PET analysis was performed

correlates with the response [10]. Therefore, FDG-PET alone showed a good potential for "early prediction" of the tumour's response, instead image fusion with combined PET/CT contributes better to the response assessment to TK inhibitors [11, 12]. In addition, FDG-PET may also early identify foci of acquired resistance in tumours which were initially responsive [13]. These clinical data suggest that the use of preclinical imaging technologies for animal models such as small animal PET, small animal CT, small animal magnetic resonance may be considered mandatory for the development of new therapeutic strategies in cancer research [14-17]. The role of small animal PET is now well recognized and the advantages of the acquisition of in vivo imaging are already reported, such as faster evaluation of molecular pathway inhibition, and faster information of prediction and assessment of the therapeutic effect $[14,15]$. At present, very few data have been published on xenograft models of GIST especially for testing the TK inhibitors activity using small animal PET $[18,19]$. 
Fig. 4 Small animal PET images (lateral, coronal and axial) of xenograft GIST882 mouse (GE, eXplore Vista DR tomograph) at 88 days from cells injection. FLT uptake (top); FDG uptake (lower part)
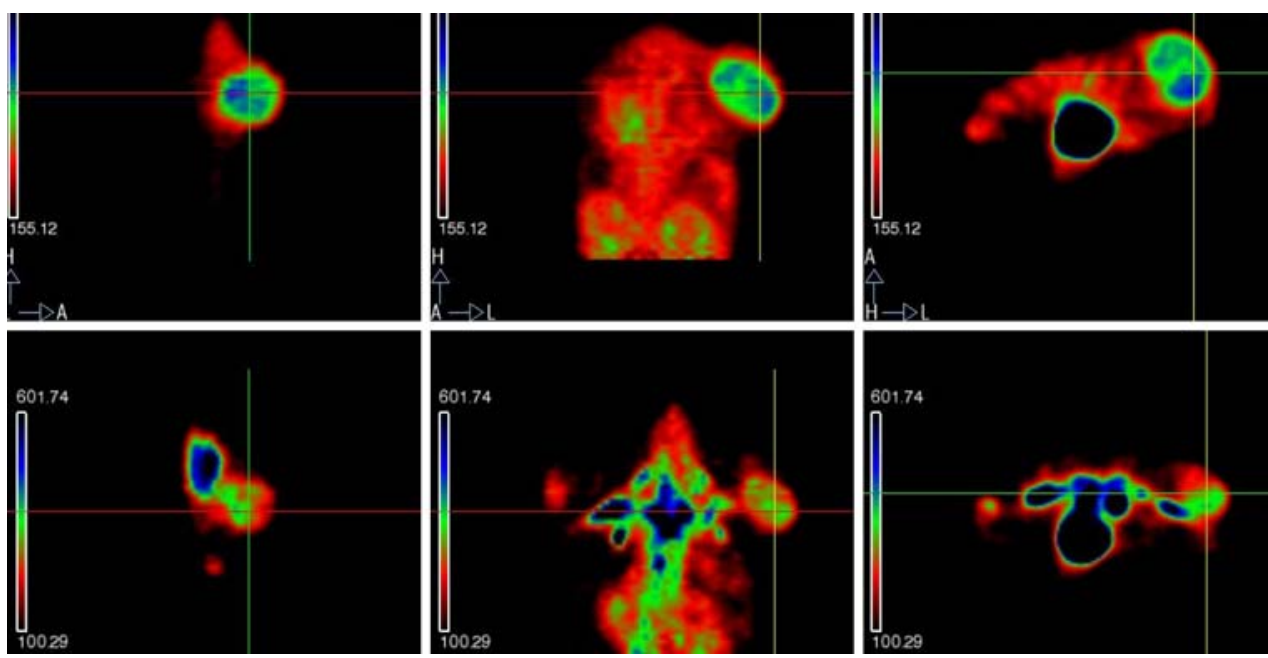

Cullinane developed a mouse model with FDC-P1 cell lines expressing two different KIT mutations that confer responsiveness (V560G) and resistance (D816V) to imatinib. The reduction of FDG uptake, resulted as the reduction of glucose transporter numbers at cell surface, was correlated to tumour response, whereas no FDG uptake modifications were correlated to tumour resistance [18]. Prenen also established a mouse model of GIST treated with imatinib evaluated with small animal PET as a promising model for comparing novel drugs or combined treatments [19]. Again, the FDG uptake decrement $24 \mathrm{~h}$ after imatinib treatments correlated to a tumour response.

As a future perspective, novel PET tracers for specifically detecting other biological functions of tumour cells such as KIT signalling or vascular endothelial growth factor receptor (VEGFr) expression need to be studied more. Kil and colleagues have recently synthesized a PET tracer labelling imatinib with ${ }^{11} \mathrm{C}$ that may be useful in monitoring the drug response and assessing the drug resistance as well [20]. That may be important for the clinical implications especially because the possible acquisition of new mutations during the natural course of metastatic disease, and in addition to the possibility of a heterogeneity of resistance mechanisms to TK inhibitors [21]. In addition, the PET imaging of VEGFr may provide information on the effect of sunitinib, even its anti-angiogenic activity in GIST is still controversial [22]. However, even though the molecular imaging perspectives seem promising, further in vivo experimental studies are needed on these tracers.

The second consideration is that the development of animal models with defined molecular background may also be considered in the preclinical setting as a modern research approach. In fact, specific molecular mechanisms has been demonstrated to predict the clinical response of GISTs to the TK inhibitors [23, 24]. Although most of the patients respond dramatically to imatinib, there is a small subset that exhibits primary resistance mainly in case of

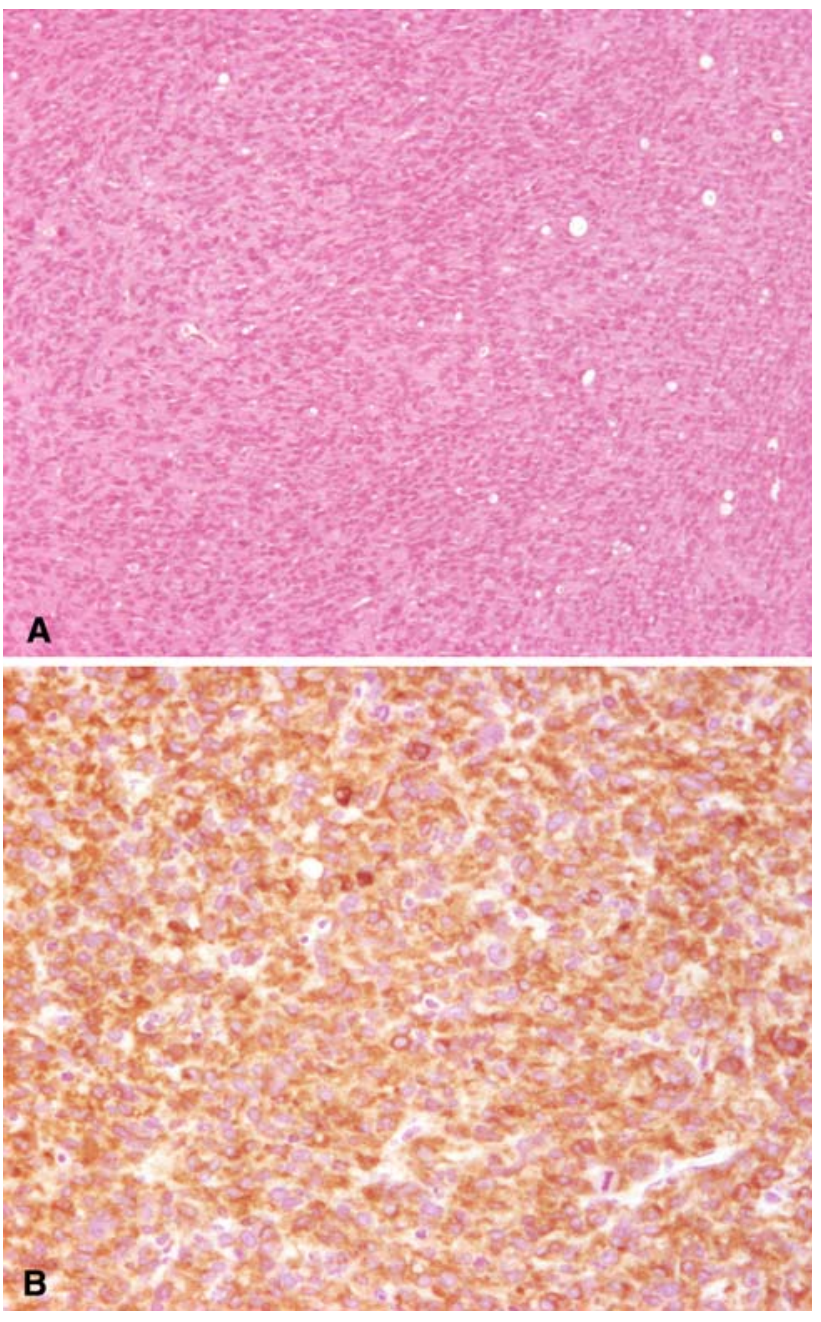

Fig. 5 Pathological evaluation of GIST tumor after mouse sacrifice. a Histological section stained with H\&E. b KIT positive immunohistochemistry

tumours with exon 9 mutant isoform protein and no detectable mutation of KIT receptor [23]. Moreover, a secondary drug resistance may also occur after a median of 
about 2 years, due to the acquisition of additional mutations of KIT or PDGFR-alfa [25, 26]. Other single agents or combined strategies are proposed to overcome the drug resistance as third or fourth line of therapy. The preclinical development of these new therapeutic strategies in GIST requires advanced preclinical models. In fact, sophisticated animal models of GIST have been developed. Recently, knock-in murine animals by introducing a germ-line gainof-function mutation of KIT receptor into the mouse genome were described [27-31]. These models are considered promising in order to investigate the role of the oncogenic signalling pathways, to study the mechanism of drugs resistance or response, or the study the up or down-regulated molecular profiles drugs mediated and the acquisition of secondary biological aberrations. Moreover, an highresolution analyses such as gene expression profiling or whole genome genotyping could be considered in in vivo experimental studies [32, 33]. The array-technologies have the advantage to screen the global genome underlying to a specific genotype. Finally, in the future the correlation between imaging features and molecular analyses data may permit to know the tumour molecular background in vivo and globally with a non invasive approach which may be potential for correctly choosing the anticancer treatments.

In conclusion, in the modern era of cancer research, the GIST model suggests that the development of new therapeutic strategies requires a multi-expertise cooperation between pathologists, oncologists, biologists, nuclear medical doctors, radio-pharmacists, radiologists and requires novel technologies for assessing better the effects of putative drugs and for developing new treatments more quickly. This approach on cancer research is crucial and essential for innovative and exciting perspectives that could cross over to other types of cancer.

Acknowledgments Special thanks to Prof. A.J. Flecther for GIST cell lines support, Boston, USA. Research programs on GIST and molecular imaging are supported by Fondazione Cassa di Risparmio of Bologna (CARISBO) and Italian Ministry of Health (Programma Integrato Oncologia 2006).

Conflict of interest statement The authors declare that they have no conflict of interest related to the publication of this manuscript.

Open Access This article is distributed under the terms of the Creative Commons Attribution Noncommercial License which permits any noncommercial use, distribution, and reproduction in any medium, provided the original author(s) and source are credited.

\section{References}

1. Hirota S, Isozaki K, Moriyama Y, Hashimoto K, Nishida T, Ishiguro S, Kawano K, Hanada M, Kurata A, Takeda M, Muhammad Tunio G, Matsuzawa Y, Kanakura Y, Shinomura Y,
Kitamura Y (1998) Gain of function mutations of c-kit in human gastrointestinal stromal tumors. Science 279:577-580

2. Lux ML, Rubin BP, Biase TL, Chen CJ, Maclure T, Demetri G, Xiao S, Singer S, Fletcher CD, Fletcher JA (2000) KIT extracellular and kinase domain mutations in gastrointestinal stromal tumors. Am J Pathol 156:791-795

3. Demetri GD, von Mehren M, Blanke CD, Van den Abbeele AD, Eisenberg B, Roberts PJ, Heinrich MC, Tuveson DA, Singer S, Janicek M, Fletcher JA, Silverman SG, Silberman SL, Capdeville R, Kiese B, Peng B, Dimitrijevic S, Druker BJ, Corless C, Fletcher CD, Joensuu H (2002) Efficacy and safety of imatinib mesylate in advanced gastrointestinal stromal tumours. N Engl J Med 347:472-480

4. Demetri GD, van Oosteroom AT, Garrett CR, Blackstein ME, Shah MH, Verweij J, McArthur G, Judson IR, Heinrich MC, Morgan JA, Desai J, Fletcher CD, George S, Bello CL, Huang X, Baum CM, Casali PG (2006) Efficacy and safety of sunitinib in patients with advanced gastrointestinal stromal tumour after failure of imatinib: a randomised controlled trial. Lancet 368 : $1329-1338$

5. Choi H, Charnsangavej C, Faria SC, Macapinlac HA, Burgess MA, Patel SR, Chen LL, Podoloff DA, Benjamin RS (2007) Correlation of computed tomography and positron emission tomography in patients with metastatic gastrointestinal stromal tumor treated at a single institution with imatinib mesylate: proposal of new computed tomography response criteria. J Clin Oncol 25:1753-1759

6. Benjamin RS, Choi H, Macapinlac HA, Burgess MA, Patel SR, Chen LL, Podoloff DA, Charnsangavej C (2007) We should desist using RECIST, at least in GIST. J Clin Oncol 25:17601764

7. Barthel H, Cleij MC, Collingridge DR, Hutchinson OC, Osman S, He Q, Luthra SK, Brady F, Price PM, Aboagye EO (2003) 3'deoxy- $3^{\prime}-[18 \mathrm{~F}]$ fluorothymidine as a new marker for monitoring tumor response to antiproliferative therapy in vivo with positron emission tomography. Cancer Res 63:3791-3798

8. Pantaleo MA, Nannini M, Lopci E, Castellucci P, Maleddu A, Lodi F, Nanni C, Allegri V, Astorino M, Brandi G, Di Battista M, Boschi S, Fanti S, Biasco G (2008) Molecular imaging and targeted therapies in oncology: new concepts of treatment response assessment. A collection of cases. Int J Oncol (in press)

9. Therasse P, Arbuck S, Eisenhauer E, Wanders J, Kaplan RS, Rubinstein L, Verweij J, Van Glabbeke M, van Oosterom AT, Christian MC, Gwyther SG (2000) New guidelines to evaluate the response to treatment in solid tumours: European Organization for Research and Treatment of Cancer, National Cancer Institute of the United States, National Cancer Institute of Canada. J Natl Cancer Inst 92:205-216

10. Stroobants S, Goeminne J, Seegers M, Dimitrijevic S, Dupont P, Nuyts J, Martens M, van den Borne B, Cole P, Sciot R, Dumez H, Silberman S, Mortelmans L, van Oosterom A (2003) ${ }^{18}$ FDGpositron emission tomography for the early prediction of response in advanced soft tissue sarcoma treated with imatinib mesylate (Glivec). Eur J Cancer 39:2012-2020

11. Antoch G, Kanja J, Bauer S, Kuehl H, Renzing-Koehler K, Schuette J, Bockisch A, Debatin JF, Freudenberg LS (2004) Comparison of PET, CT, and dual-modality PET/CT imaging for monitoring of imatinib (STI571) therapy in patients with gastrointestinal stromal tumours. J Clin Med 45:357-365

12. Goerres GW, Stupp R, Barghouth G, Hany TF, Pestalozzi B, Dizendorf E, Schnyder P, Luthi F, von Schulthess GK, Leyvraz S (2005) The value of PET, CT, and in line PET/CT in patients with gastrointestinal stromal tumours: long-term outcome of treatment with imatinib mesylate. Eur J Nucl Med Mol Imaging 32: $153-162$ 
13. Van den Abbeele AD (2008) The lessons of GIST-PET and PET/ CT: a new paradigm for imaging. Oncologist 13(supp12):8-13

14. Nanni C, Rubello D, Fanti S (2007) Role of small animal PET for molecular imaging in pre-clinical studies. Eur J Nucl Med Mol Imaging 34:1819-1822

15. Boss DS, Olmos RV, Sinaasappel M, Beijnen JH, Schellens JH (2008) Application of PET/CT in the development of novel anticancer drugs. Oncologist 13:25-38

16. Greschus S, Kiessling F, Lichy MP, Moll J, Mueller MM, Savai R, Rose F, Ruppert C, Günther A, Luecke M, Fusenig NE, Semmler W, Traupe H (2005) Potential applications of flat-panel volumetric CT in morphologic and functional small animal imaging. Neoplasia 7:730-740

17. Reynolds CP, Sun BC, DeClerek YA, Moats RA (2005) Assessing growth and response to therapy in murine tumor models. Methods Mol Med 111:335-350

18. Cullinane C, Dorow DS, Kansara M, Conus N, Binns D, Hicks RJ, Ashman LK, McArthur GA, Thomas DM (2005) An in vivo tumor model exploiting metabolic response as a biomarker for targeted drug development. Cancer Res 65:9633-9636

19. Prenen H, Deroose C, Vermaelen P, Sciot R, Debiec-Rychter M, Stroobants S, Mortelmans L, Schöffski P, Van Oosterom A (2006) Establishment of a mouse gastrointestinal stromal tumor model and evaluation of response to imatinib by small animal positron emission tomography. Anti cancer Res 26:1247-1252

20. Kil KE, Ding YS, Lin KS, Alexoff D, Kim SW, Shea C, Xu Y, Muench L, Fowler JS (2007) Synthesis and positron emission tomography studies of carbon-11-labeled imatinib (Gleevec). Nucl Med Biol 34:153-163

21. Liegl B, Kepten I, Le C, Zhu M, Demetri G, Heinrich M, Fletcher C, Corless C, Fletcher J (2008) Heterogeneity of kinase inhibitor resistance mechanisms in GIST. J Pathol 216:64-74

22. Wang H, Cai W, Chen K, Li ZB, Kashefi A, He L, Chen X (2007) A new PET tracer specific for vascular endothelial growth factor receptor 2. Eur J Nucl Med Mol Imaging 34:2001-2010

23. Heinrich MC, Corless CL, Demetri GD, Blanke CD, von Mehren M, Joensuu H, McGreevey LS, Chen CJ, Van den Abbeele AD, Druker BJ, Kiese B, Eisenberg B, Roberts PJ, Singer S, Fletcher CD, Silberman S, Dimitrijevic S, Fletcher JA (2003) Kinase mutations and imatinib response in patients with metastatic gastrointestinal stromal tumor. J Clin Oncol 21:4342-4349

24. Heinrich MC, Maki RG, Corless CL, Antonescu CR, Harlow A, Griffith D, Town A, McKinley A, Ou WB, Fletcher JA, Fletcher CD, Huang X, Cohen DP, Baum CM, Demetri GD (2008) Primary and secondary kinase genotypes correlate with the biological and clinical activity of sunitinib in imatinib-resistant gastrointestinal stromal tumor. J Clin Oncol 33:5352-5359

25. Antonescu CR, Besmer P, Guo T, Arkun K, Hom G, Koryotowski B, Leversha MA, Jeffrey PD, Desantis D, Singer S, Brennan MF, Maki RG, DeMatteo RP (2005) Acquired resistance to imatinib in gastrointestinal stromal tumor occurs through secondary gene mutation. Clin Cancer Res 11:4182-4190

26. Heinrich MC, Corless CL, Blanke CD, Demetri GD, Joensuu H, Roberts PJ, Eisenberg BL, von Mehren M, Fletcher CD, Sandau K, McDougall K, Ou WB, Chen CJ, Fletcher JA (2006) Molecular correlates of imatinib resistance in gastrointestinal stromal tumors. J Clin Oncol 24:4764-4774

27. Nakai N, Ishikawa T, Nishitani A, Liu NN, Shincho M, Hao H, Isozaki K, Kanda T, Nishida T, Fujimoto J, Hirota S (2008) A mouse model of a human multiple GIST family with KITAsp820Tyr mutation generated by a knock-in strategy. J Pathol 214:302-311

28. Rubin BP, Antonescu CR, Scott-Browne JP, Comstock ML, Gu Y, Tanas MR, Ware CB, Woodell J (2005) A knock-in mouse model of gastrointestinal stromal tumors harboring kit K641E. Cancer Res 65:6631-6639

29. Sommer G, Agosti V, Ehlers I, Rossi F, Corbacioglu S, Farkas J, Moore M, Manova K, Antonescu CR, Besmer P (2003) Gastrointestinal stromal tumors in a mouse model by targeted mutation of the Kit receptor tyrosine kinase. Proc Natl Acad Sci USA 100:6706-6711

30. Rossi F, Ehlers I, Agosti V, Socci ND, Viale A, Sommer G, Yozgat Y, Manova K, Antonescu CR, Besmer P (2006) Oncogenic KIT signalling and therapeutic intervention in a mouse model of gastrointestinal stromal tumors. Proc Natl Acad Sci USA 103:12843-12848

31. Gunawam B (2008) Knock-in murine models of familial gastrointestinal stromal tumours. J Pathol 214:407-409

32. Antonescu CR, Viale A, Sarran L, Tschernyavsky SJ, Gonen M, Segal NH, Maki RG, Socci ND, DeMatteo RP, Besmer P (2004) Gene expression in gastrointestinal stromal tumours is distinguished by KIT genotype and anatomic site. Clin Cnacer Res 10:3282-3290

33. Meza-Zepeda LA, Kresse SH, Barragan-Polania AH, Bjerkehagen B, Ohnstad HO, Namløs HM, Wang J, Kristiansen BE, Myklebost O (2006) Array comaparative genomic hybridization reveals distinct DNA copy number differences between gastrointestinal stromal tumors and leiomiosarcomas. Cancer Res 66: 8984-8993 